\title{
Ocular Complications from Retained Intraocular Ointment Discovered 33 Months after Cataract Surgery
}

\author{
Riley N. Sanders David B. Warner Lindsey R. Adams Ahmed A. Sallam \\ Sami H. Uwaydat \\ Jones Eye Institute, University of Arkansas for Medical Sciences, Little Rock, AR, USA
}

\section{Keywords}

Cystoid macular edema - Endothelial cell loss - Optical coherence tomography · Specular microscopy $\cdot$ Intraocular ointment

\begin{abstract}
Topical antibiotic and steroid ointments are sometimes used topically at the conclusion of intraocular surgery, and inadvertent entry into the eye has been reported. Dispersed ointment droplets or consolidated globules in the anterior chamber (AC) can sometimes be visualized on exam. Occasionally, intraocular ointment is found incidentally without apparent toxic effect, but retained ointment usually presents with early or delayed intraocular inflammation, pressure rise, macular edema, or corneal edema. The usual treatment for toxicity from retained ointment is removal of the ointment. While the complication of ointment-induced cystoid macular edema has been reported, there is paucity of literature on the anatomical response and eventual visual outcome of patients who have been treated for long-standing edema from retained ointment. We present a case of a patient who presented with history of poor vision since the time of cataract surgery 33 months prior, who had cystoid macular edema, reduced endothelial cell count, and apparent Maxitrol ointment (neomycin, polymyxin B sulfate, and dexamethasone in paraffin vehicle; Novartis Pharmaceuticals UK) floating in the AC. The patient was treated with $\mathrm{AC}$ washout and sub-Tenon injection of triamcinolone. His vision, retinal architecture by optical coherence tomography, endothelial cell count, and pachymetry has been followed for 9 months following this treatment.




\section{Introduction}

Intraocular ointment has been reported as a complication of cataract surgery in cases where ointment is placed on the eye at the conclusion of surgery. Retained ointment in the eye can cause toxic anterior segment syndrome (TASS), endothelial decompensation, chronic cystoid macular edema (CME), uveitis, and elevated intraocular pressure (IOP) [1]. The ointment may be visible as an ovoid mass floating within the anterior chamber (AC) [1], or adherent to the implanted intraocular lens (IOL) [2]. Patients may present with TASS in the first postoperative day or have a more subtle presentation weeks to months after their cataract surgery [1]. Identification of the ointment has been accomplished using electron microscopy, gas chromatography-mass spectroscopy [1], Fourier transform infrared, and confocal Raman microspectroscopies [2].

We present a case in which a patient presented with chronic CME 34 months after his cataract surgery and was found to have Maxitrol ointment (neomycin, polymyxin B sulfate, and dexamethasone in paraffin vehicle, Novartis Pharmaceuticals UK) in the AC. This case has one of the longest durations of retained intraocular Maxitrol ointment causing intraocular toxicity evidenced by CME and endothelial cell loss.

\section{Case History}

A 74-year-old man presented to our eye institute complaining of decreased vision in the left eye (OS). He had undergone sutureless cataract surgery at an outside facility 33 months prior to his presentation, and Maxitrol ointment was placed on the eye at the conclusion of surgery. He reported that his vision had remained poor postoperatively. On his first visit to our clinic, his best corrected visual acuity (BCVA) was 20/200 OS, and optical coherence tomography (OCT) (Cirrus HD-OCT, Zeiss, Germany) showed intraretinal fluid in the fovea with a central retinal thickness of $647 \mu \mathrm{m}$ (Fig. 1A). Fluorescein angiography showed petalloid dye leakage around the fovea and late staining of the optic disc consistent with Irvine-Gass syndrome (Fig. 1B). Closer examination of the anterior segment revealed a small oval foreign body floating in the AC (Fig. 2), most consistent with retained intraocular ointment. No deposits on the IOL were seen. The jelly-like mass was aspirated under topical anesthesia in the operating room using a blunt cannula through a clear corneal wound, while IOP was maintained with an AC maintainer (see online suppl. video, www.karger.com/doi/10.1159/000495002). Liquid chromatography was not available to analyze the mass. Thirteen days postoperatively, the patient was seen in clinic and OCT revealed persistent CME. An injection of $40 \mathrm{mg}$ Kenalog into the sub-Tenon's space was done. The patient was then seen 5 weeks postoperatively, with the OCT showing resolution of the CME, central retinal thickness of $231 \mu \mathrm{m}$, and a normal retinal architecture (Fig. 3B).

The patient has been followed for over 9 months without recurrence of CME, with a BCVA of 20/70 at distance in the affected eye. Preoperative endothelial cell count was not available, but specular microscopy (CellChek XL, Konan Medical USA) was performed 6 months after the AC washout, showing a decreased endothelial cell count in OS to 476 cells $/ \mathrm{mm}^{2}$, compared to 2,513 OD (Fig. 3B). Pachymetry by CellChek was $596 \mu \mathrm{m}$ OD and $590 \mu \mathrm{m}$ OS. 


\section{Discussion}

Following reports of accidental postsurgical entry of ointment into patient eyes in the 1960 s, researchers injected rabbit eyes with various common ointment vehicles and observed them for development of corneal edema, uveitis, or glaucoma. They found that all ointment bases were variably toxic, depending on their composition and the amount left inside the eye [3].

The characteristic appearance of retained ointment within the AC is oily particles on the iris, or an ovoid globule floating near the angle [4]. A case report has also described intraocular garamycin ointment that was discovered 34 months after cataract extraction as a "hump" adhering to the anterior surface of the IOL, which blocked the visual axis. The patient recovered to 20/25 Snellen vision after IOL exchange with no evidence of ocular toxicity [2].

Retained intraocular ointment has been reported to cause a variety of problems related to toxicity, including TASS and elevated IOP [1]. A globule of intraocular chloramphenicol ointment has been observed for 6 years inside a patient's AC before the development of CME necessitating AC washout [4]. Some patients with ointment in the AC also develop corneal endothelial cell loss [5]. In another case where Maxitrol ointment remained in the AC for 2 years, a patient developed anterior uveitis and elevated IOP, but without CME and with normal endothelial cell count [6].

Our patient presented 33 months after cataract surgery with CME and an AC mass consistent with ointment. Though chromatography was unavailable, the operative note indicated that Maxitrol ointment was placed at the conclusion of surgery, and the appearance on exam is identical to previous reports $[4,5,7]$. This is one of the longest durations that Maxitrol ointment has been left inside the AC, causing ocular toxicity evidenced by CME and decreased endothelial cell count.

Our patient had no IOL deposits and was treated with AC washout and a local steroid injection. His CME resolved and retinal architecture appears grossly normal (Fig. 3A); however, there was permanent corneal endothelial damage as evidenced by the specular microscopy (Fig. 3B). Luckily, in 9 months of follow-up, the patient has not developed clinically evident corneal edema or increasing pachymetry as a result of the endothelial cell loss. Distance BCVA better than 20/70 has not been achieved with multiple refractions. Given the clarity of the cornea and optical media, and no known history of amblyopia, this is probably attributable to either retinal toxicity or disorganization in cellular connections not readily seen on OCT.

Topical medications placed at the conclusion of sutureless cataract surgery can enter the AC by several mechanisms. Negative pressure from the speculum removal or eye rubbing can aspirate the ointment into the AC [8]. Diurnal IOP fluctuations have also been proposed as a risk factor for drawing material into a fresh wound [6].

Toxic effects of the ointment derive from the medication's vehicle, and severity depends on the type and amount left within the eye. In the experiments done with ointment bases injected into rabbit eyes, petrolatum/paraffin (used in Maxitrol, and most other ophthalmic ointments) appeared more harmful than peanut oil or mineral oil, but less toxic than Aquaphor or hydrous wood fat [3].

It has been suggested by some authors that small amounts of retained intraocular ointment can safely be observed until complications arise [9]. In select cases, this may be appropriate. Because toxicity can present in different ways, we recommend that if observation is exercised, it should include not only checking the vision and IOP, but also periodic gonioscopy, macular OCT, pachymetry, and endothelial cell counts. 


\section{Conclusion}

Although CME from retained intraocular ointment can be reversed following removal of the ointment, endothelial cell loss can be permanent. Lost endothelium can lead to corneal decompensation and stromal edema necessitating endothelial transplant or penetrating keratoplasty surgery. There may also be retinal toxic effects not easily seen on ophthalmoscopy or OCT. With our technique, the ointment was aspirated within a few minutes under topical anesthesia, representing a relatively low-risk procedure. Therefore, prompt removal of retained intraocular ointment, once identified, is highly recommended.

\section{Statement of Ethics}

The authors have no ethical conflicts to disclose.

\section{Disclosure Statement}

This work was sponsored in part by an endowment from the Martha Wood Bentley Chair in Ophthalmology. None of the authors has any conflict of interest related to the publication of this paper.

\section{References}

1 Werner L, Sher JH, Taylor JR, Mamalis N, Nash WA, Csordas JE, et al. Toxic anterior segment syndrome and possible association with ointment in the anterior chamber following cataract surgery. J Cataract Refract Surg. 2006 Feb;32(2):227-35.

2 Chen KH, Lin SY, Li MJ, Cheng WT. Retained antibiotic ophthalmic ointment on an intraocular lens 34 months after sutureless cataract surgery. Am J Ophthalmol. 2005 Apr;139(4):743-5.

3 Scheie HG, Rubenstein RA, Katowitz JA. Ophthalmic ointment bases in the anterior chamber. Arch Ophthalmol. 1965 Jan;73(1):36-42.

4 Lee EJ, Wong R, Laidlaw DA. Late-onset cystoid macular edema associated with small-incision cataract surgery and inadvertent entry of chloramphenicol ointment into the anterior chamber. Ophthalmic Surg Lasers Imaging. 2010 Mar;42:1-3.

5 Mansour AM, Haddad RS, Salti HI, Habbal Z. Optical coherence tomography findings in anterior chamber ointment globule after phacoemulsification. Case Rep Ophthalmol. 2015 Dec;6(3):469-76.

6 Wong VW, Chu KO, Lam PT, Yam GH, Lai TY. Late appearance of an intracameral ophthalmic ointment globule after uneventful phacoemulsification. Jpn J Ophthalmol. 2009 Sep;53(5):553-5.

7 Kudo A, Kudo T, Takahashi D, Metoki T, Suzuki Y, Nakazawa M. Macular edema associated with intraocular ointment after cataract surgery. Am J Ophthalmol Case Rep. 2018 Mar;10:152-5.

8 Wong JG, Bank A. Surgical removal of intraocular antibiotic ointment after routine cataract phacoemulsification. J Cataract Refract Surg. 2006 May;32(5):890-2.

9 Humayun M, Gottlieb CC, Rafuse PE. Intraocular ophthalmic ointment following clear corneal phacoemulsification: clinical implications. J Cataract Refract Surg. 2006 Dec;32(12):2135-8. 


\section{Case Reports in Ophthalmology}

www.karger.com/cop

Sanders et al.: Ocular Complications from Retained Intraocular Ointment Discovered 33 Months after Cataract Surgery
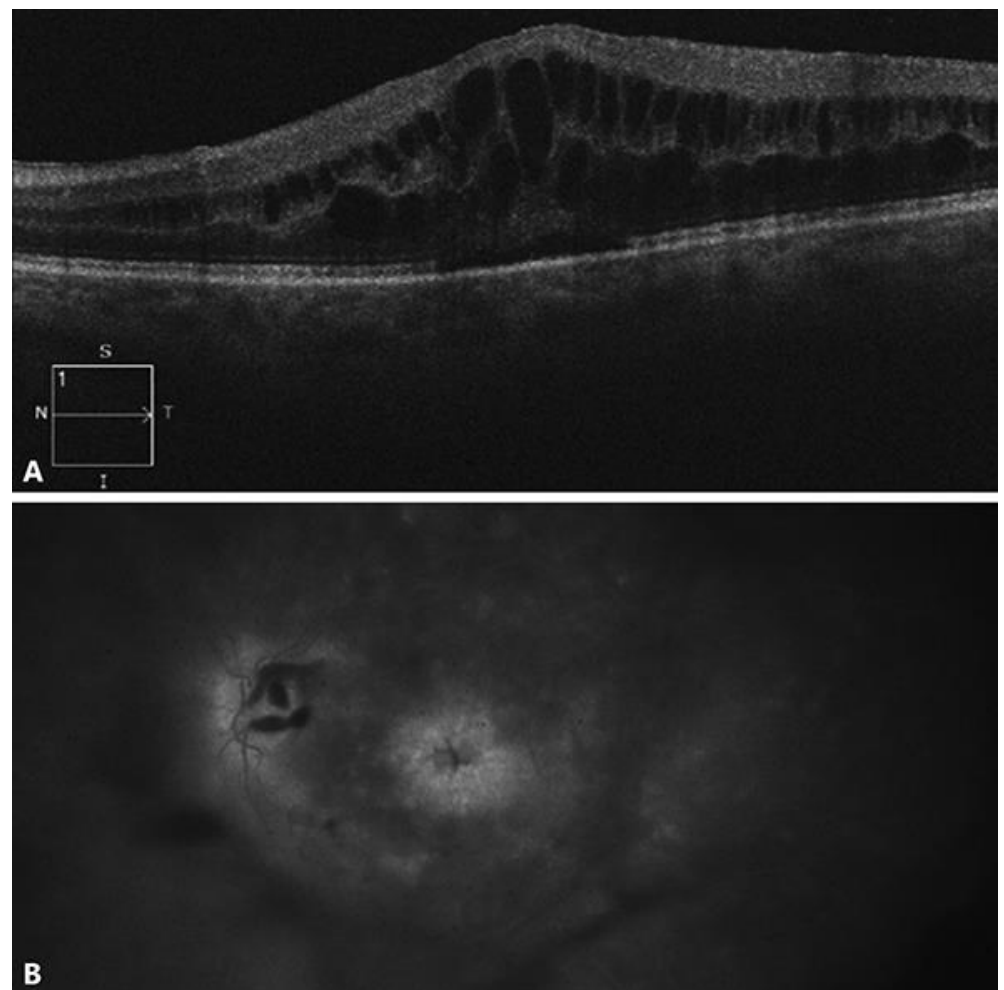

Fig. 1. Studies done on presentation. A Preoperative OCT showing intraretinal cystic spaces overlying the fovea, with a central retinal thickness of $647 \mu \mathrm{m}$. B Late-phase fluorescein angiography showing radially arranged leakage in the macula and staining of the optic disc.

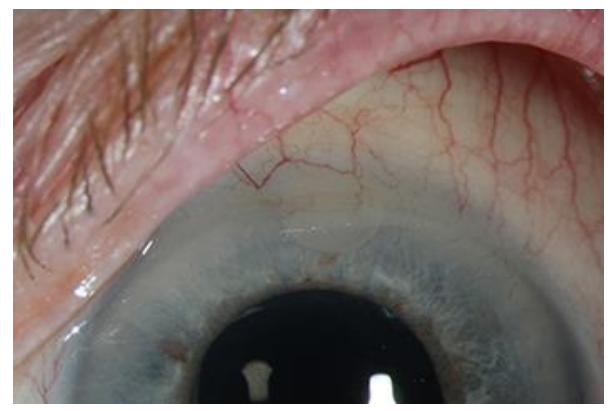

Fig. 2. Slit-lamp photograph of pearlescent globule in superior angle. 


\section{Case Reports in Ophthalmology}
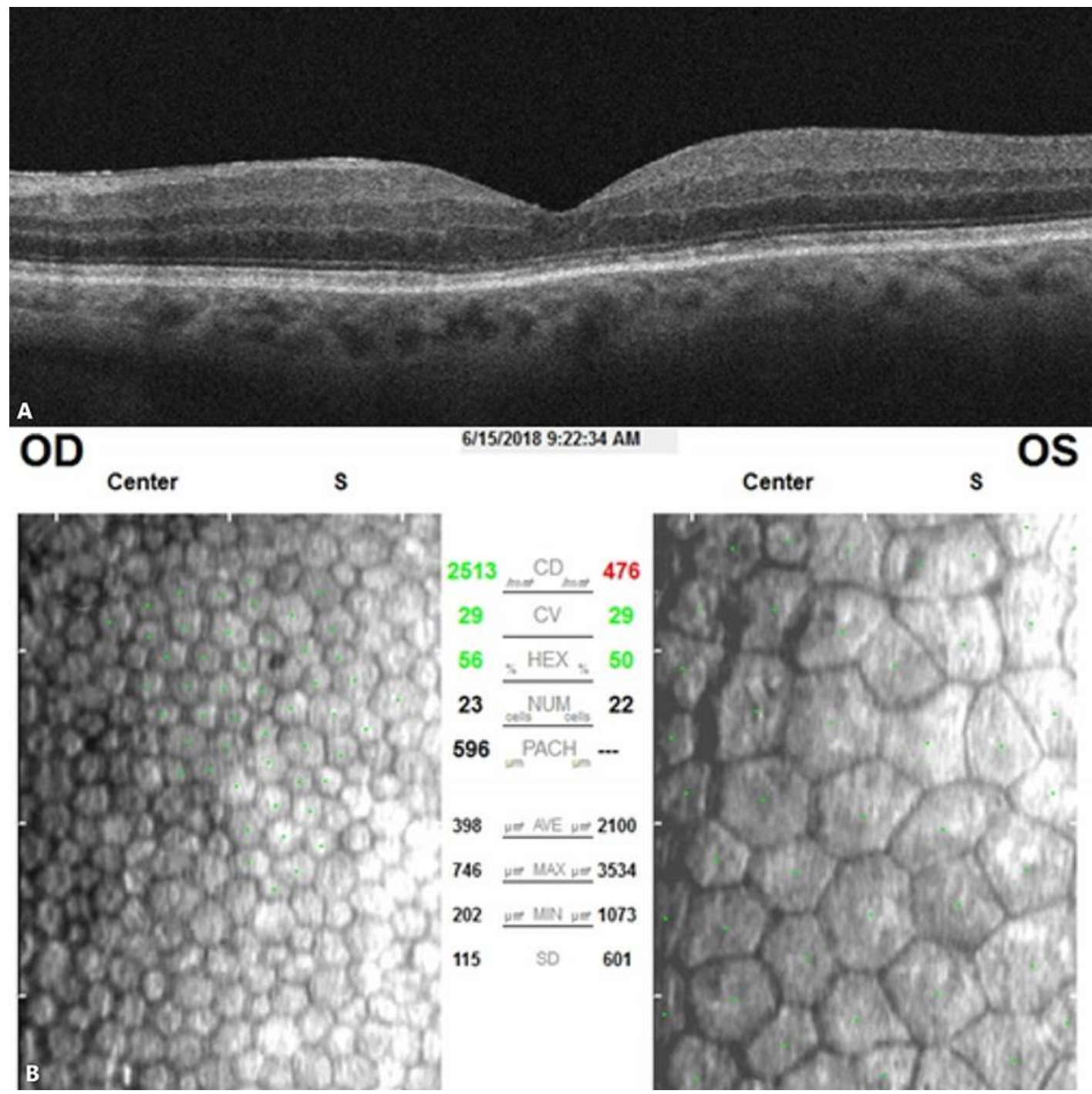

Fig. 3. Studies after ointment removal and sub-Tenon's Kenalog. A SD-OCT image through fovea showing resolution of edema and return of relatively normal retinal architecture. B Spectral microscopy with endothelial cell count, showing decreased cell density of OS. Reexamination later showed pachymetry of 590 in OS. The similarity in the pachymetry suggests that there is no corneal edema from endothelial decompensation. 